\title{
Are active labour market policies effective in activating and integrating low-skilled individuals? An international comparison
}

\author{
Verónica Escudero ${ }^{1,2}$ (D)
}

\author{
Correspondence: escudero@ilo.org \\ ${ }^{1}$ Research Department, International \\ Labour Organization (ILO), 4 route \\ des Morillons, CH-1211 Geneva 22, \\ Switzerland \\ ${ }^{2}$ Paris School of Economics (PSE) \\ Paris, France
}

\begin{abstract}
This paper examines the effectiveness of active labour market policies (ALMPs) in improving labour market outcomes, especially of low-skilled individuals, by means of a pooled cross-country and time series database for 31 advanced countries during the period 1985-2010. The analysis includes aspects of the delivery system to see how the performance of ALMPs is affected by different implementation characteristics. Among the notable results, the paper finds that ALMPs matter at the aggregate level, but mostly through an appropriate management and

implementation. In this regard, sufficient allocation of resources to programme administration and policy continuity appear to be particularly important. Moreover, start-up incentives and measures aimed at vulnerable populations are more effective than other ALMPs in terms of reducing unemployment and increasing employment. Interestingly, the positive effects of these policies seem to be particularly beneficial for the low skilled.

JEL Classification: J08, E24, H5, J68, D78

Keywords: Active labour market policies, Implementation, Unemployment rate, Low skilled, OECD, Aggregate effects
\end{abstract}

\section{Introduction}

Since the 1990s, there has been an increased acceptance in the developed world of the need for ALMPs to strengthen the link between social protection, labour market policies and employment. Today, these policies are widely regarded as an important tool in fighting unemployment. As a result, expenditure in ALMPs is sizeable in most advanced economies and continues to increase. Success of ALMPs, however, has not been invariably positive. Although some empirical evidence exists that points to a positive effect on the probability of finding employment (e.g. Layard et al. 2009; Lalive et al. 2005; Larsen 2002), the effects tend to be relatively small, making it unclear whether the positive outcomes are enough to compensate for the costs. Moreover, a central concern that remains is whether ALMPs are suitable to address longer-term matters such as skills and employability, especially among the least employable jobless individuals.

This paper aims to contribute to this debate by examining the effectiveness of active labour market policies (ALMPs) in improving labour market outcomes, especially for

(c) The Author(s). 2018 Open Access This article is distributed under the terms of the Creative Commons Attribution 4.0 International License (http://creativecommons.org/licenses/by/4.0/), which permits unrestricted use, distribution, and reproduction in any medium, provided you give appropriate credit to the original author(s) and the source, provide a link to the Creative Commons license, and indicate if changes were made. 
low-skilled individuals from a macroeconomic perspective. The analysis is done by ways of a pooled cross-country and time series analysis based on 31 advanced countries ${ }^{1}$ for which detailed annual data on different ALMPs (putting particularly emphasis on those specifically targeted to low-skilled individuals) exists for the period 1985-2010. The study contributes to the empirical evaluation of ALMPs beyond what it is already known mainly in three ways: first, the paper includes aspects of the delivery system in the analysis to shed light on the role of implementation characteristics in explaining differences in the performance of ALMPs between countries. Second, it disaggregates the analysis by type of ALMP to capture their differential effects. Third, it is focused on the labour market outcomes of low-skilled individuals that have been among the least researched marginalized groups. Lastly, the paper provides an updated aggregate assessment approach by extending the time and country coverage of the dataset, ${ }^{2}$ thereby unveiling new estimates of the overall net effect of ALMPs in the labour market.

Much has been written about the effectiveness of active labour market measures based on evaluations carried out using micro-data, yet not enough about their effectiveness at the aggregate level. In fact, a well-established microeconomic literature exists today on the effects of these policies and their design and delivery systems at the individual level (Card et al. 2010 and 2017). In particular, the evidence to date suggests that training and private sector employment programmes have been generally effective, but mostly in the medium to long-term, while in the short-term effects are negligible. Meanwhile, job search assistance tends to have similarly positive impacts in the short and long runs. On the contrary, public work schemes have not proved very effective. For all types of active interventions, findings from micro-econometric analyses show that the design, targeting and implementation of a policy are paramount in ensuring its effectiveness (ILO 2016).

At the macroeconomic level, conversely, much less research exists that allows to understand whether ALMPs matter in broad terms. As the role of ALMPs frequently involve substitution, displacement and other indirect effects, which generally cannot be addressed by microeconomic policy evaluations, capturing empirically the overall net effect of ALMPs on the wide labour market (i.e. including both on the efficiency of the matching process and on the size of the labour force) is of upmost importance. This comprehensive assessment of the effects of ALMPs is, however, nearly absent in today's literature. First, some studies exist on the macroeconomic effects of labour market institutions and reforms, of which ALMPs are one component (e.g. Murtin and de Serres 2014; Blanchard and Wolfers 2000; Scarpetta 1996). This literature owes its origin to the innovative analysis of Layard et al. (1991), which studied the effect of activation on the structural unemployment rate, finding that ALMPs have a negative effect on longterm unemployment. Second, there are a few other studies that focus particularly on the effects of ALMPs, yet with no consensus with regard to the effect of these policies on unemployment rates. While the seminal study of the Organisation for Economic Co-operation and Development (OECD) (1993) argues that results are not robust enough to be conclusive, Estevão (2003) found positive effects of ALMPs on the employment rate of the business sector in the 1990s (but not in the late 1980s), Baker et al. (2005) found only an insignificant impact and Bassanini and Duval (2006) find that some types of ALMPs, such as labour market training, are indeed associated with lower unemployment. Moreover, these studies have focused on whether total ALMP spending 
matters at the aggregate level, but (except for Bassanini and Duval 2006) ${ }^{3}$ without delving into the great variation in effectiveness between different types of policies. This constitutes the third stream of the literature, where only a handful of studies have been documented that assess the overall effects of ALMPs while disaggregating between the different policies (Martin 2015). Finally, studies in which the effectiveness of ALMPs is linked to implementation aspects are even scarcer (Schmid et al. 2001; Calmfors 1994; de Koning and van Nes 1991). As such, existing knowledge on the aggregate effects of different ALMPs and the role played by design and implementation aspects in shaping those effects remains inconclusive.

Deepening the understanding of the broader effects of ALMPs is, however, all the more relevant today. First, the persisting labour market consequences of the Great Recession has brought to the fore a renewed interest in the potential role of ALMPs in easing a wide range of labour market problems (Martin 2015; Armingeon 2007). Second, many advanced countries are under tight budgets, and given the mixed empirical evidence on the effectiveness of ALMPs, spending on these policies is under careful scrutiny. Third, the availability of longer time series allows to control better the sensitivity of policies to the business cycle (Schmid et al. 2001). ${ }^{4}$ As such, the potential for capturing the full effects of ALMPs and deepening the understanding of their effectiveness has increased of late. Based on these new developments, the present paper is a renewed effort to capture the overall effects of ALMPs at a macroeconomic level with views to assessing their impact on the efficiency of the matching process and on the size of the labour force, while also taking into consideration their indirect effects (i.e. productivity and competition effects, deadweight loss, substitution, crowding-out and lock-in effects).

I find that ALMPs matter at the aggregate level, including through appropriate implementation aspects. Start-up incentives and the cluster of policies aimed for the most vulnerable (job rotation, supported employment and direct job creation measures) show the most favourable results, both in terms of reducing unemployment and also in terms of increasing employment. They are also effective in raising participation, but only for the low skilled. Spending in employment incentives is also effective across the board, again with the exception of raising participation for the overall group, where the effect is not statistically significant. Importantly, results show that ALMPs are more effective for the low skilled than for the overall population; something that is noteworthy as we know little from the existing literature on the net effects on these policies on low-skilled individuals. Training, in contrast, seems to be effective mostly for the overall population; however, it has also positive effects for the low skilled through the interaction with implementation variables. In terms of implementation, the analysis finds that the allocation of resources to programme administration has favourable effects and that a disruption of policy continuity is associated with negative effects for all labour market variables analysed. Interestingly, the size of the coefficients arising from policy and implementation variables, once interactions are included, is noticeably higher, demonstrating that a correct implementation of policies enhances their beneficial effect.

\section{Theoretical and empirical considerations}

From the theoretical point of view, the traditional justification for ALMPs has been to reduce labour market imbalances and counteract rigidities and distortions. This comes 
from the recognition that governments cannot address sustainably unemployment through demand expansion alone (Bellmann and Jackman 1996a). ALMPs are therefore needed, first, to facilitate the matching process between the supply and demand for labour so that a given number of jobseekers will be associated with fewer vacancies; second, to maintain the level of effective labour supply by keeping the long-term unemployed and other groups of 'outsiders' tight to the labour force; third, to affect the demand for labour, therefore increasing the number of available jobs; and fourth, to boost the productivity of the labour force, both through the direct effect of ALMPs on programme participants and also through general productivity increases associated with externalities. ${ }^{5}$

Naturally, the direction and magnitude of these effects would depend on the specific type of measure put in place and its target group. ${ }^{6}$ Placement services and all types of job-search assistance benefit the labour market not only through an increased search effectiveness (Schmid et al. 2001; Bellmann and Jackman 1996b) but also from increases in the number of vacancies since opening posts becomes less costly for firms (Pissarides 1990; Calmfors and Lang 1995). Meanwhile, labour supply-oriented measures (including training, workers' subsidies etc.) are expected to have little, if any, impact on the level of unemployment (Schmid 1996). Yet, they could have a stronger impact on the structure of unemployment by reducing skill bottlenecks and the vulnerability of groups that are more exposed to risks in the labour market, such as the unskilled or long-term unemployed (OECD 1993). These measures could also reduce search efforts among participants in the expectation that the course culminates (i.e. lock-in effect) (Bellmann and Jackman 1996b).

Particularly relevant for this paper, ALMPs that focus on vulnerable groups can be effective by raising participants' employability and providing them with incentives to search harder for jobs, thereby leading to lower reservation wages, which can stimulate the labour demand and facilitate employment (Bellmann and Jackman 1996a). However, in the absence of specific components aimed to raise employability, these types of ALMPs could result in wage moderation and even in an increase in the number of working poor (Clasen and Clegg 2006). Moreover, in times of crisis, a given level of aggregate employment needs to be assumed, which would reduce the effectiveness of ALMPs, i.e. ALMPs could lead to substitution and displacement effects due to the lack of new available jobs. Under these circumstances, a stricter targeting on disadvantaged groups can be justified economically by its potential to affect specific groups even if the aggregate effects of ALMPs are low (de Koning 2001).

Empirically, on the other hand, evidence from international comparisons (e.g. crosscountry and time series analyses) on the impact of ALMPs has been contentious. Historically, there has been a major disagreement between the proponents of this approach on the medium-term policy reaction function that realistically predicted policy spending patterns of governments. This had important implications not only for the definition of policy variables but also for the solution proposed for the simultaneity bias (reverse causality) that usually plagues labour market policy analyses. ${ }^{7}$ During the 1990s, this disagreement resulted in two clearly opposed theoretical frameworks. The first one assumed that governments based their decisions on a fix level of ALMP spending per unemployed person, which could vary slightly over time but that did not adjust fully with unemployment (Layard et al. 1991). Thus, they suggested to look at 
average unemployment rates and average levels of spending on ALMPs per unemployed person over the medium term. The second theoretical framework assumed that governments committed a given fraction of GDP to ALMP spending over the medium term, which did not adjust with the unemployment rate (OECD 1993). As such, ALMP spending was measured as a share of GDP.

Importantly, different assumptions about the governments' policy stance yielded different results with regard to the effect of ALMPs on unemployment rates. While Layard et al. (1991) found that ALMPs had a reducing effect on long-term unemployment, the OECD (1993) argued that results were not robust enough to be conclusive. Unfortunately, it is still far from clear what a correct representation of the policy reaction function is and it might well be the case that whatever the representation, it would not be the same across countries. Conscious of this problem, other efforts arose later using different definitions of the policy variables depending on the context and tackling the reverse causality issue mainly through fixed-effects estimators and instrumental variables (Büttner and Prey 1997; Schmid et al. 2001; Estevão 2003; Bassanini and Duval 2006). Still, effects are mixed, and thus, the knowledge on the aggregate effects of ALMPs remains inconclusive. This paper is a renewed effort to contribute to filling these gaps in the literature.

\section{Evolution of ALMPs}

Since the 1990s, there has been a growing interest in ALMPs. Today, expenditure in ALMPs is sizeable in most advanced economies and continues to increase. Between 2004 and 2009, ALMP expenditure grew continuously at an average annual rate of 5.8\%, reaching an accumulated growth of $32.5 \%$ and a total spending of US $\$ 176.5$ billion (PPP) in the 5 years to 2009. Only in 2010, this expansion was interrupted and ALMP spending fell by close to 0.7\% (Fig. 1). ALMP spending per unemployed individual has also increased in a sustained manner, by an accumulated 25.5\% between 2004 and 2008. In 2009 and 2010, however, this upward trend ended abruptly due to the rise in the number of unemployed as a consequence of the crisis.

In terms of the distribution of expenditure by type of policy, an important share of spending on ALMPs (excluding Public Employment Service (PES) and administration) ${ }^{8}$ remained concentrated in training measures, which represented close to $39 \%$ of the total in 2010 (Fig. 2). Spending in employment incentives, direct job creation and supported employment and rehabilitation measures also represented prominent shares (between 16 and 22\% each). Meanwhile, the share of expenditure in start-up incentives was much lower (at $6.2 \%$ of total expenditure) and that of job rotation and job sharing programmes was negligible. Relative to 2004, the different types of policies have maintained their relative importance, with minor exceptions. For example, a small decrease in the share of spending in supported employment and rehabilitation measures seems to have given way to an increase in spending in direct job creation.

The overall growth in expenditure on ALMPs during the period 2004-2010 was driven by training, in spite of a decrease in its share in 2010. It accounted for one third of the total increase in ALMP spending (excluding PES and administration) during the period. Employment incentives and direct-job-creation measures are the second and 

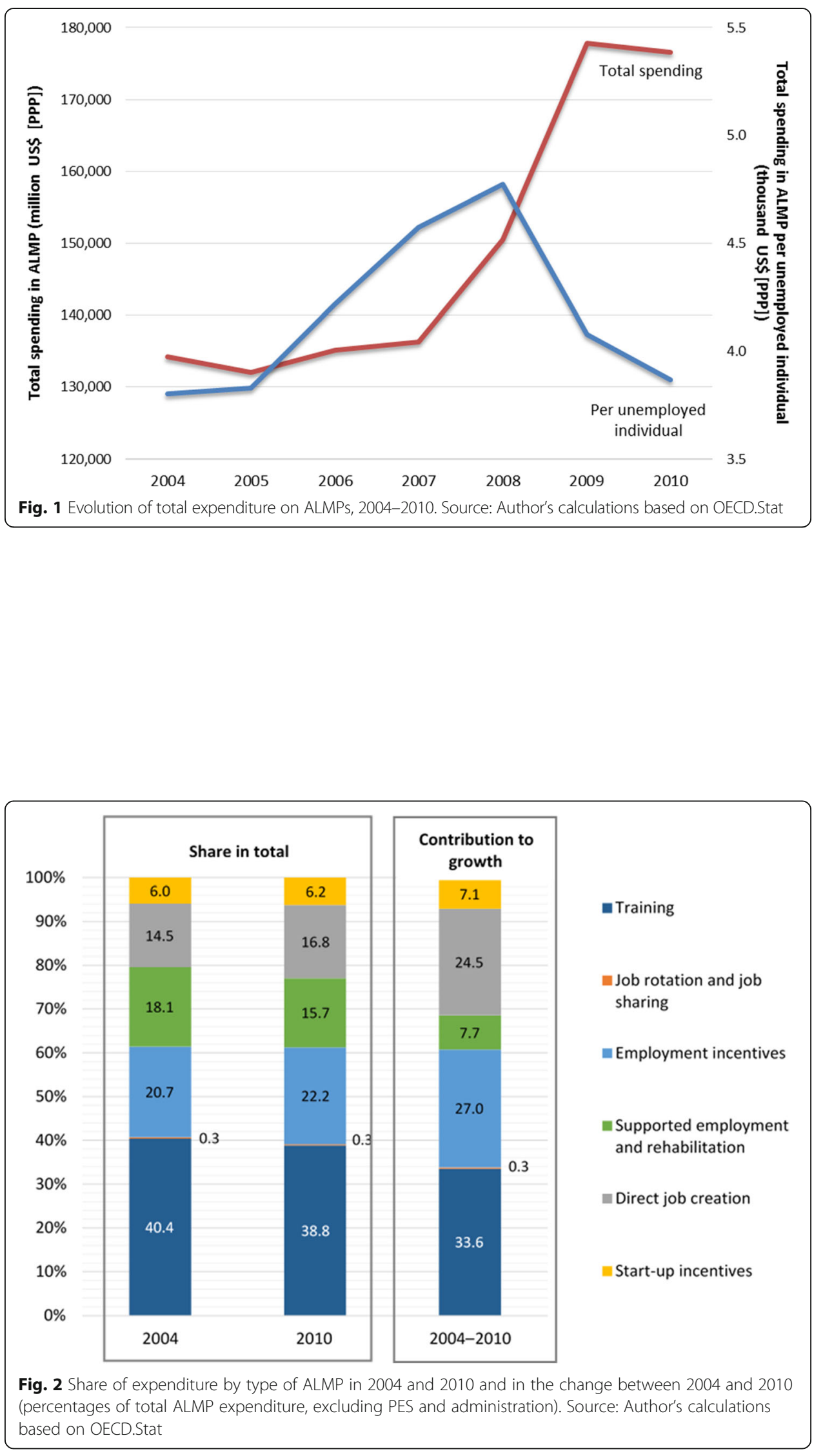
third sources of growth in ALMP expenditure, accounting for around 27 and 24.5\% of the total increase, respectively. Conversely, spending in supported employment and rehabilitation fell during the period; thus, its contribution to growth only accounted for $7.7 \%$.

In sum, training continues to be the preferred tool of governments to address labour market problems in advanced countries. Meanwhile, employment incentives and direct-job-creation measures have become more prominent. The remaining of this paper will test whether targeting spending towards these priority policies is indeed the most effective way to address labour market challenges.

\section{Empirical specification}

4.1 Description of the model

In order to assess how effective ALMPs are in improving labour market outcomes, especially for low-skilled individuals, this paper uses a panel data model based on a reduced-form equation with the following simple form:

$$
\mathrm{LM}=f(\mathrm{ALMP}, \mathrm{IMPL}, \mathrm{DC}, \mathrm{STRUC}, \mathrm{INST}, \mathrm{EU})
$$

where LM includes six labour market indicators, selected as dependent variables. The first three measure labour market outcomes of the overall population and include the unemployment rate, the employment-to-population ratio and the labour force participation rate (LFPR). The second three include these same variables but calculated specifically for low-skilled individuals.

ALMP comprises the active labour market policy variables. As discussed above, determining the correct representation of the policy stance of governments is a fundamental step to define the policy variable used in the analysis. I found that, in the panel of countries analysed in this paper, there is a positive correlation between total ALMP spending and unemployment but a negative correlation between ALMP spending per unemployed individual and unemployment. This would be consistent with a mediumterm policy reaction function of governments regarding ALMP spending, which is based on a fixed level of expenditure per unemployed individual, that could be somewhat adjusted based on a cyclical component (Layard et al. 1991). Following this policy stance, one would argue that the appropriate policy intervention measure should be defined as real expenditure on ALMPs per unemployed person as this measure is adequate to describe the intensity of policies in a comparative setting (Heylen 1993; Bellmann and Jackman 1996b). ${ }^{9}$ However, in order to limit the spurious correlation that arises between the policy and labour variables, the findings discussed in the paper are based on the specification that uses the lagged values of the ratio as instruments for the policy variables.

Importantly, different policies can produce different effects depending on their objective, design and population targeted. To capture this, the analysis includes different types of ALMPs. Particularly, the six different types of ALMPs were classified into four groups, training, employment incentives, a policy cluster comprising policies mainly targeted to the most vulnerable groups (including job rotation and job sharing, supported employment and rehabilitation, and direct job creation policies) and start-up incentives. The policy cluster was computed in order to deal with the multicollinearity arising between policy variables. For each category, the variable (i.e. real expenditure per 
unemployed person) was converted to international dollars using purchasing power parity (PPP) exchange rates, to ensure comparability across countries.

One of the novelties of this paper is the inclusion of implementation-related variables (IMPL) in the analysis. It can be expected that the effectiveness of ALMPs will hinge (at least partly) on their design and implementation (de Koning 1993). To account for this, three indicators were constructed capturing different dimensions of implementation: (i) the magnitude of resources allocated to the administration and implementation of ALMPs, ${ }^{10}$ as well-resourced policies are expected to be more effective since they are better equipped to deliver labour market services more systematically. This first dimension is measured by the overall expenditure on programme administration ${ }^{11}$ as a percentage of total expenditure in ALMPs; (ii) continuity in the implementation of programmes is also expected to matter since large fluctuations in public spending (i.e. exceeding cyclical swings) are likely to compromise the stability of implementation, which would be detrimental in terms of effectiveness (Schmid 1996). Continuity is measured by the dynamics of ALMP expenditure compared to that of the economy; as such, large annual variations in ALMP spending (fluctuations that exceed cyclical swings) would be the antithesis of continuity in implementation; and finally, (iii) a variable timing is included to measure whether policies are implemented in a countercyclical or pro-cyclical manner (Schmid 1996). To assess this, a dummy variable was created taking the value of 1 if expenditure on ALMPs ran parallel to changes in the unemployment rate and counter the economic trend (i.e. policies that were implemented countercyclically) and 0 otherwise.

Importantly, implementation variables are closely related to policy intervention ones. To avoid a misspecification arising from the omission of these relationships, three interaction terms were included in the specification: training*PES allocation; incentives"PES allocation; ALMP*timing. ${ }^{12}$ An additional interaction term was added between the variables cycle $^{13}$ and timing to capture the fact that countercyclical policies may be more effective depending on the moment of the economic cycle.

The remaining three groups of variables are controls: DC includes terms of trade and year dummies to account for changes in the demand conditions. Although using GDP or output gap is most common, one can expect that these covariates will be highly correlated with both labour market variables and policy variables. This will reduce the scope for ALMPs to predict labour market outcomes as well as loading the empirical analysis with an endogeneity problem (Overesch and Rincke 2011; Bassanini and Duval 2009).

Moreover, the structure of national labour markets (STRUC) is considered since it can influence structural changes and the speed of adjustment to shocks. To take these differences into account, the concentration of the population on a particular skill level (measured by the share of the population with tertiary education) was included to account for an increase in policy effectiveness when populations are highly educated since highly educated individuals have more probabilities to find a job. In addition, four controls for differences in institutional arrangements (INST) were also included in the estimation: union density, to control for insider power in wage bargaining, which may push wages upwards at a cost of lower employment, especially for groups whose labour supply is more elastic (e.g. low-skilled workers) (Layard et al. 2009); the two indexes of strictness of EPL, one for the layoff of temporary workers, since temporary layoff regulation can reduce search effectiveness of the unemployed (Bellmann and 
Jackman 1996b), and another for the individual and collective dismissal of regular workers, as ALMP effectiveness can also be affected by the coexistence of different levels of EPL stringency between temporary and regular contracts (Dolado et al. 2002); and an average of gross replacement rates across various earnings levels, family situations and durations of unemployment to reflect the generosity of the unemployment benefit system and account for its interaction with ALMPs (Bassanini and Duval 2006; Martin and Grubb 2001). Finally, EU countries have a relatively integrated labour market due to a relative freedom in the movement of workers. To control for this special feature of the European labour market, a dummy variable was added taking the value of 1 for countries that are members of the European Union (EU). The variables used in the analysis draw from different sources of information. The exact definitions and sources can be found in Additional file 1: Table S1. ${ }^{14}$ Furthermore, a summary of descriptive statistics of the variables used in the analysis are also presented in Additional file 1: Table S4.

\subsection{Empirical strategy}

The analysis consists of a pooled cross-country and time series database for 31 advanced countries with yearly information during the period 1985-2010. Six different models were estimated to measure the effectiveness of ALMPs. The first three measure the effects of ALMPs on labour market outcomes of the overall population and the other three the effects on the specific target group of this analysis, the low skilled.

There has been an expansion in the use of panel data analyses in recent years, explained first, by the fact that they allow to capture both spatial and temporal features in the analyses, as well as the interaction between these two dimensions (Hijzen and Martin 2013; Halla et al. 2016). Second, they rely less on highly variable covariates, while allowing for a greater statistical power thanks to the increase in the number of observations (Escudero and López Mourelo 2017), something that is all the more relevant today that we count with longer time series. Third, the last decade has seen an important development of tools and methodologies to treat a wider range of empirical problems, making these methods more robust when assessing aggregate effects. ${ }^{15}$

Nonetheless, cross-sectional time series data analyses can also be plagued by several problems such as heteroskedasticity across panels, serial correlation in the idiosyncratic error terms, unobserved country-specific effects, etc. This type of assessment thus necessitates a comprehensive empirical strategy that implements the different steps necessary to test and take account of these potential issues in a systematic manner. This paper aims to implement this systematic approach. As a first step of the empirical strategy, I estimate the six models using pooled ordinary least squares (OLS). In reality, OLS estimators can rarely be unbiased when estimated in a panel data context, but they are usually estimated first as they represent a benchmark to compare the size of coefficients and standard errors of additional specifications. Second, I estimate the six models using fixed- or random-effects. I examine the suitability of the random- or fixed-effects specification using the Hausman test. In all cases, a correlation of the entities' error terms with the regressors is found, which invalidates the use of randomeffects. Fixed-effects models are thus used to avoid any biases arising from excluding unobservable country-specific effects that are correlated with other covariates (Escudero and López Mourelo 2017). In a third step, for each specification, I use the ArellanoBond post-estimation technique (abar) (Roodman 2006) and the Lagrange-Multiplier 
test (Wooldridge 2010; Drukker 2003) to assess the presence of serial correlation in the idiosyncratic error terms, which is usually expected in macro panels with long time series like the one used in this paper, especially as a result of omitting variables that change progressively over time (Lusinyan and Bonato 2007). Given that the results of these tests confirmed the presence of first-order autocorrelation (AR1) (which also implies that OLS, random- and fixed-effects models are biased and/or inconsistent, as they underestimate standard errors of the coefficients), I use an additional estimator in all six specifications, a feasible generalized least squares model (FGLS) fitted for panel data. FGLS constitutes an appropriate additional benchmark as it admits the presence of AR1 autocorrelation within panels, cross-sectional correlation and heteroskedasticity across panels in the estimation. ${ }^{16}$ Importantly, all models were estimated with controls for unobservable time-specific effects in order to account for labour market shifts that are common to all countries as a result of macroeconomic factors.

Finally, as discussed above, reverse causality is a common issue in labour market policy analyses as it is not only ALMPs that affect unemployment but it may also be the case that changes in unemployment influence expenditure in ALMPs. Under this circumstance, it has been widely demonstrated that coefficients estimated through fixed effects might be inconsistent and biased, since they are based on the assumption of strict exogeneity. To address this potential specification problem, a final step of the estimation strategy consisted in carrying out an instrumental variable (IV) approach through a two-stage least squares (2SLS) estimator.

There is a large literature on the risks of getting biased estimates due to the potential reverse causality that is latent in ALMP analyses. In the literature, this has been typically handled by either normalizing ALMPs to a fixed fraction of GDP over the medium term (Murtin and de Serres 2014; Estevão 2003) or by using country-specific averages of ALMP expenditures over the period analysed (Baker et al. 2005; Elmeskov et al. 1998; Bellmann and Jackman 1996b). Although these methods have clear advantages, they also have important weaknesses. While the former solution assumes a policy stance that is not a correct representation of reality (at least not in the panel of countries used for this study, as discussed above), the latter eliminates the time varying property of the policy variables as a source of identification, something that is particularly worrying in this analysis giving the long period studied. More recently, studies have moved towards the use of instruments as an exogenous variation for the effect of ALMPs, taking advantage of the technical advances in this area, particularly during the last decade (Dahlberg and Forslund 2005). In an effort to tackle reverse causality without compromising the correct policy variable, this paper follows this more recent approach, using as instruments the lagged values of the policy variables.

In particular, the unemployment, employment and LFPR models were estimated instrumenting two of the four policy variables (training and policy cluster) ${ }^{17}$ and the implementation-related variable continuity through a two-stage least squares (2SLS) estimator. I used the lagged values of the endogenous variables as instruments, in addition to the other exogenous variables of the model. A key question for the analysis is whether these instruments are relevant and valid or, in other words, whether they satisfy the two key assumptions, namely, being correlated with the endogenous variables but uncorrelated with the error term. Intuitively, I find that lagged variables are an interesting solution in this case because while labour market variables may affect 
and be affected by ALMP's expenditure, current labour market variables have no effect on past ALMP's conditions (Agnolucci et al. 2017). In addition, there is no reason to believe that the past values of the endogenous ALMP variables would affect labour market variables through other channels than the present ALMP values. More formally, these two assumptions were tested with encouraging results.

Regarding the first assumption or the relevance of the instruments, Additional file 1: Table S2 provides a summary of the first-stage regressions, showing a strong and significant correlation of each of the endogenous policy variables with the instruments (i.e. the $F$ test statistics for additional instruments are above the 10-point conventional levels, all with $p$ values of 0.00$).{ }^{18}$ Moreover, the Anderson-Rubin test provides proof that the instruments are collectively strongly correlated with the included endogenous regressors (Baum et al. 2007). In terms of the second assumption, I tested the validity of instruments in an over identified context and their exclusion restrictions through the J-statistic of the Hansen test (Table 1). The test confirmed the validity of the group of instruments used in each model, implying that they are suitable and that they satisfy the condition of orthogonality with the error process (Wooldridge 2010). Finally, it is worth noting that all 2SLS models were estimated with controls for unobserved country-specific effects and used the gmm and robust options to compute efficient estimates in the presence of heteroskedasticity and serial correlation.

\section{Results}

Table 1 reports the effects of ALMP expenditures on the unemployment, employment and labour force participation rates (LFPR) of the overall and low-skilled populations. The table includes results using the three specifications mentioned above that control for time- and country-specific effects (i.e. OLS, FGLS with AR1 correction, and the IV models) to show the overall consistency of results. The effects discussed in this section correspond to those of the IV estimation (2SLS), which is the preferred specification. Having discussed the results of the first-stage regressions, which support the validity of the instruments, what follows discusses the results of the second-stage IV estimates on the different labour market indicators. The comparability of these results with those of the OLS and FGLS models is discussed in Section 5.2.

\subsection{Description of results}

\subsubsection{Effects on the unemployment rate}

Estimates relative to the unemployment rate show that the policy cluster, employment incentives and start-up incentives have a significant negative effect on the unemployment rates of the overall and low-skilled populations. The effect of training is also negative and significant, but only for the overall population. Interestingly, with the exception of training, ALMPs seem to be more effective in reducing the unemployment rate of the low skilled than that of the overall population.

These findings are consistent with empirical evaluations carried out using microdata, which suggest that subsidized employment programmes have positive average impacts especially in the medium to long terms (Card et al. 2017). In fact, sometimes, the positive effects of these programmes even exceed the effects of training (Kluve 2010), but this is not systematic in the literature. Likewise, start-up incentives have been found 


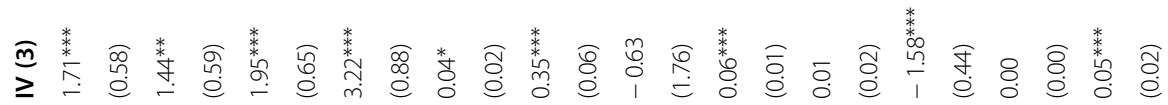

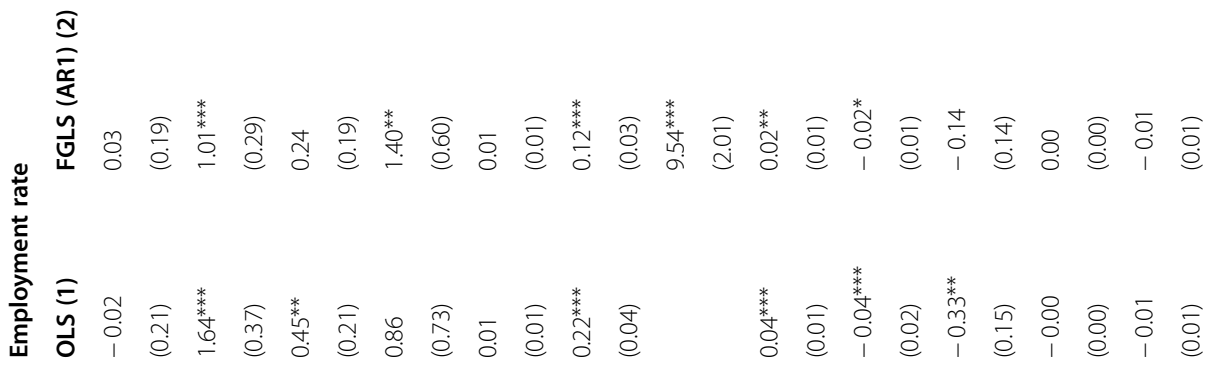

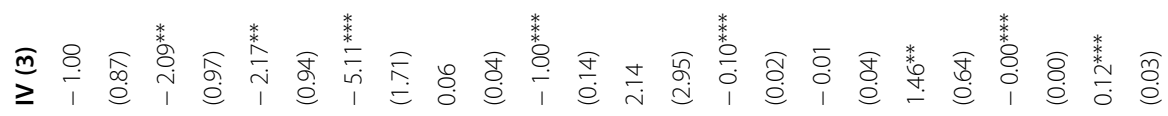

苋

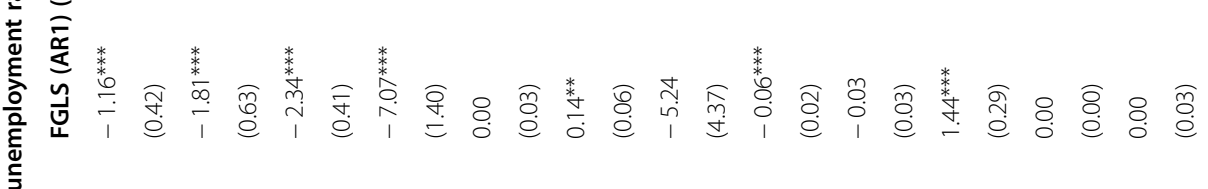
焉

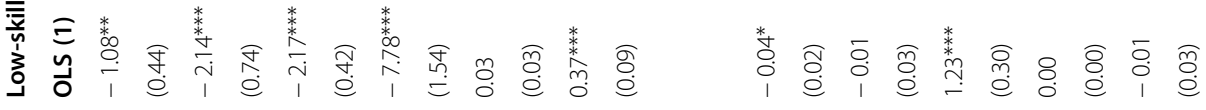

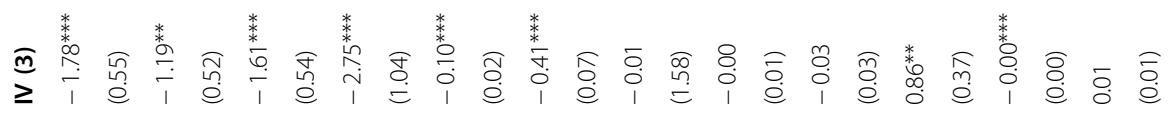

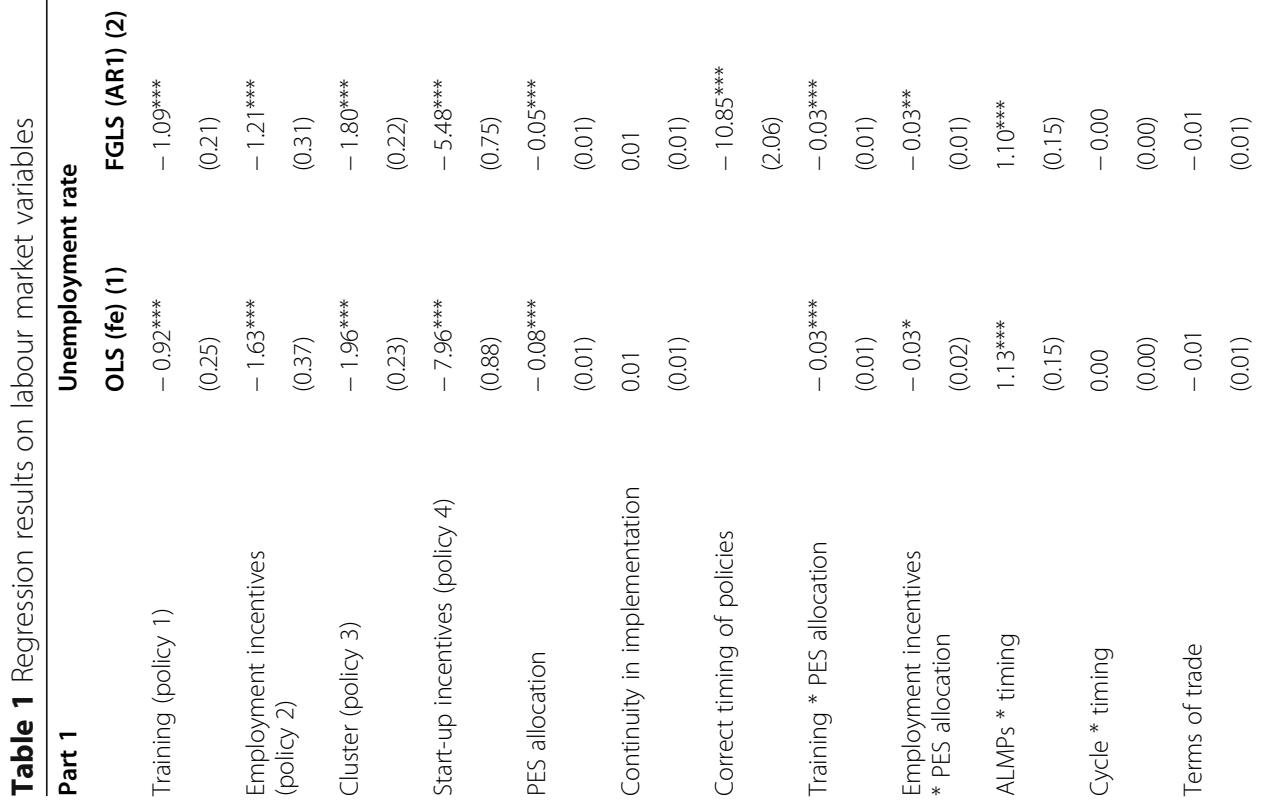




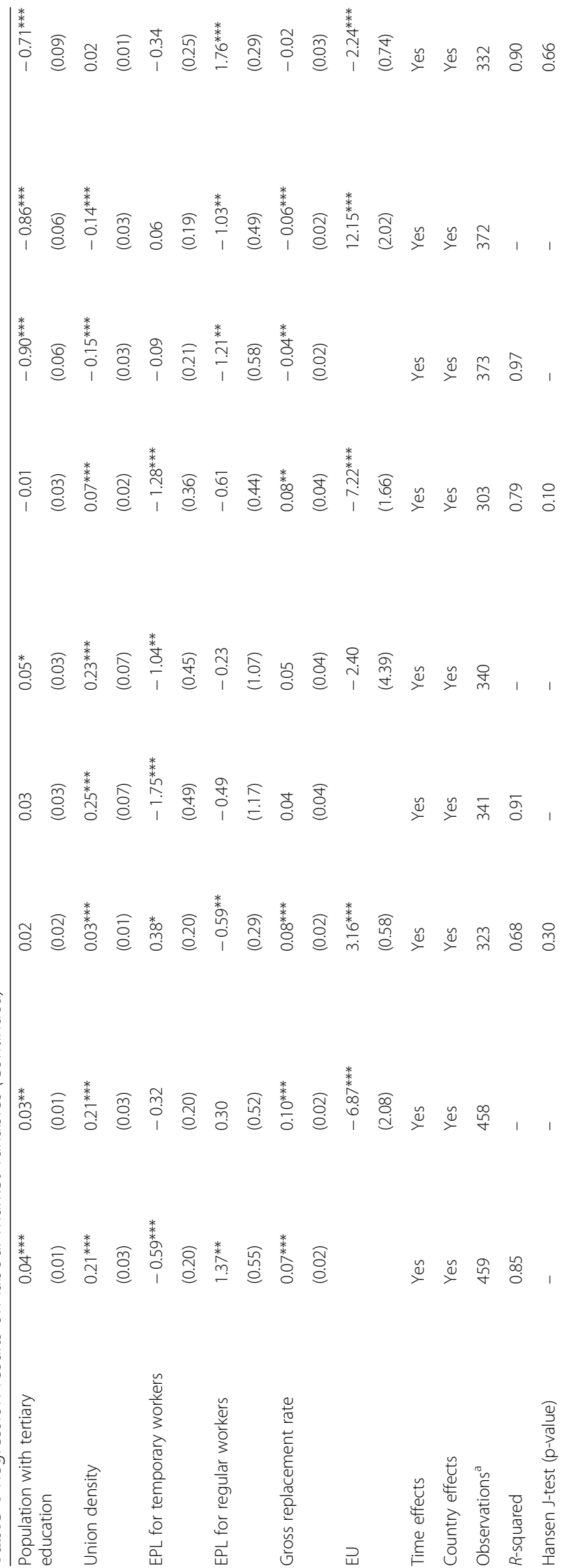




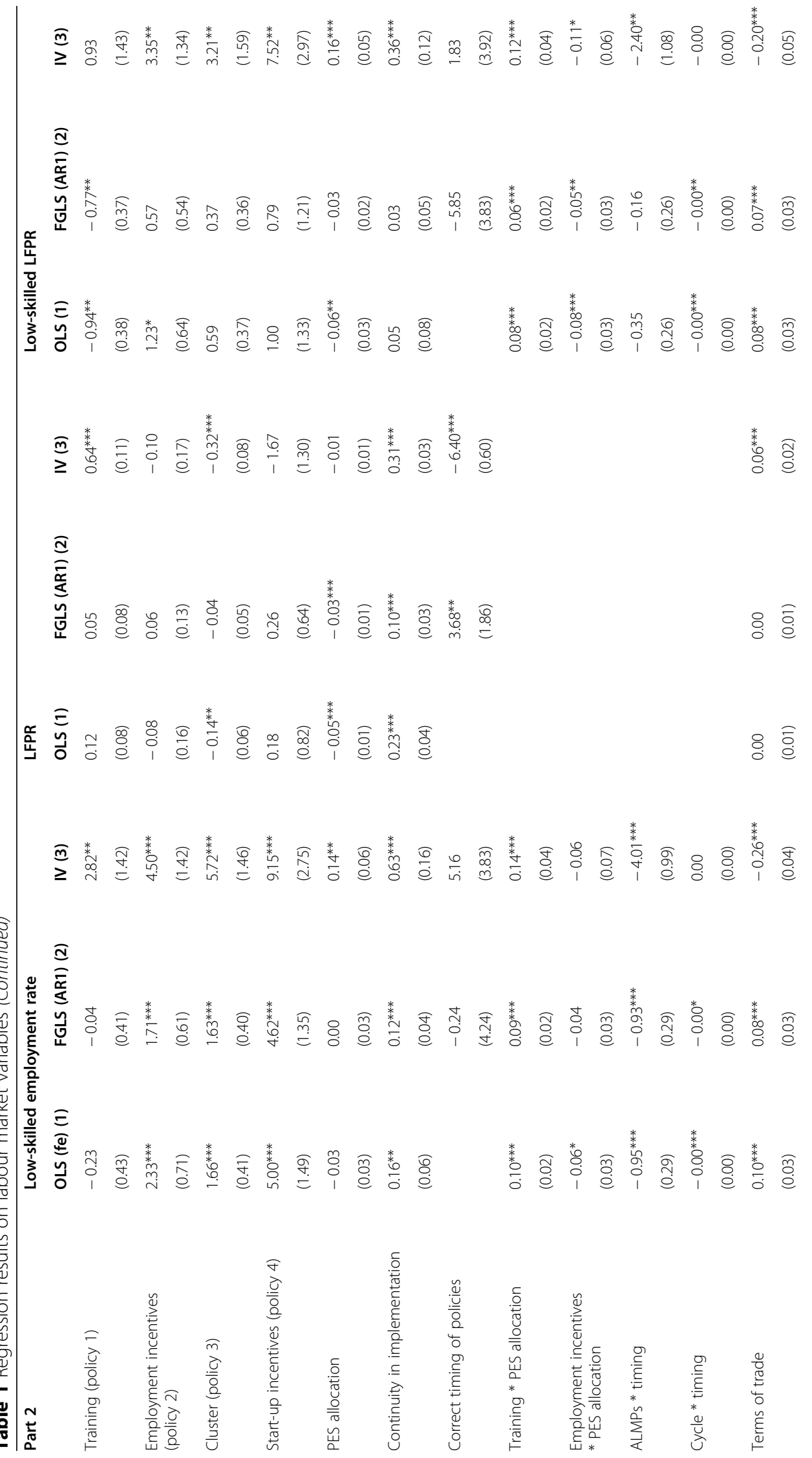




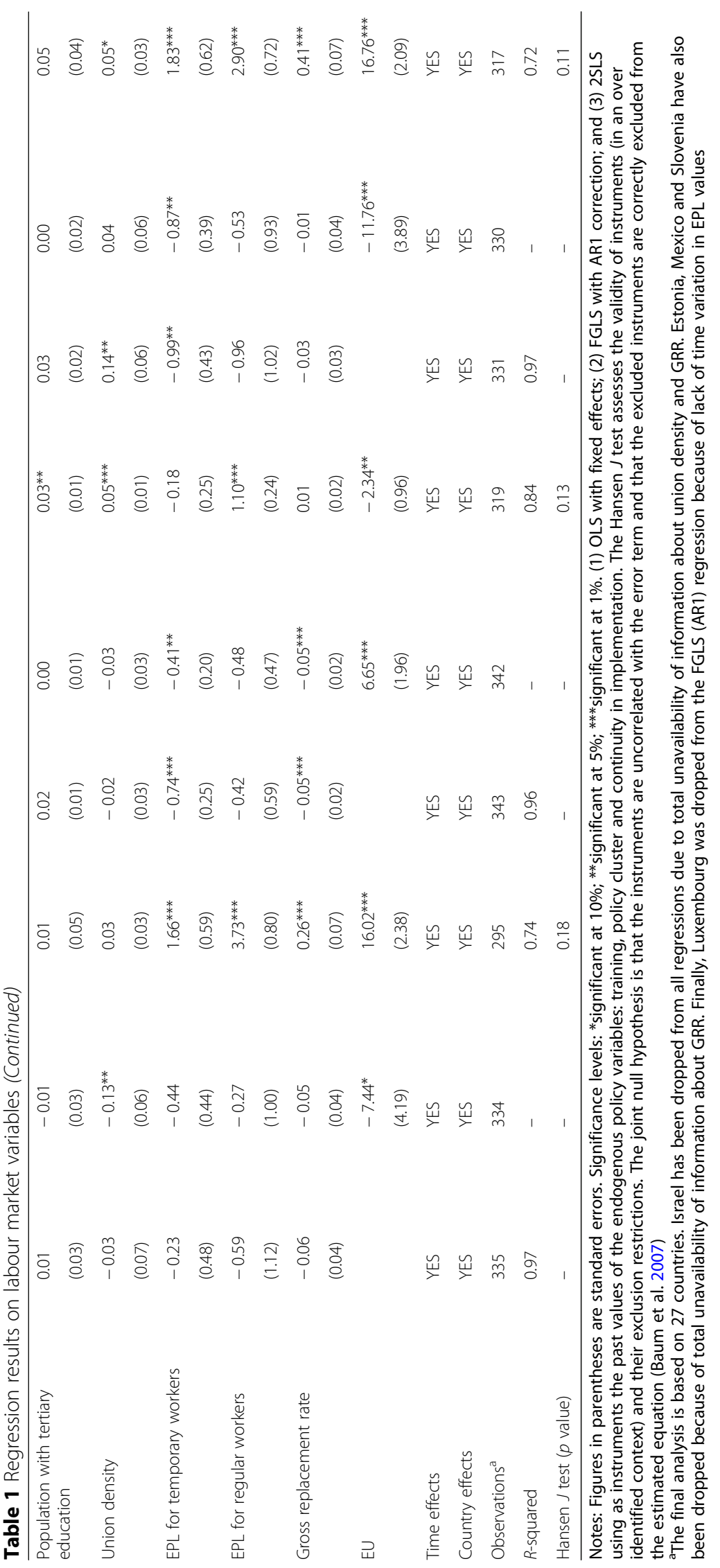


to be effective in advanced countries (Caliendo and Künn 2014; Caliendo and Künn 2011; Card et al. 2017). Moreover, as in this paper, a number of studies have found that start-up incentives are more effective for disadvantaged persons, particularly for the low educated, who face limited options in the labour market (Caliendo and Künn 2011; Rodriguez-Planas 2010). ${ }^{19}$ Finally, public works (main category of the policy cluster) usually have a poor performance or even negative effects in micro-econometric analyses (Card et al. 2010; Algan et al. 2002). Yet, public employment has also been credited with mitigating job losses caused by high wage floors (Kahn 2012). Indeed, when these policies focus on marginal groups, they may indeed have positive effects, given their higher likelihood of being accompanied by substitution and displacement effects (ILO 2016).

The implementation of ALMPs seems to matter too. Raising the allocation of resources to programme administration has a reducing effect on the unemployment rate, either directly or through its interaction with policy variables. This finding supports the conclusions from a number of micro-econometric studies carried out in OECD countries that show consistently positive outcomes from investing in PES (Martin and Grubb 2001). Interestingly, this paper finds that while the variable PES allocation only affects the unemployment rate of the overall population directly, it has a significantly negative effect for the unemployment rate of the low-skilled group through its interaction with training. This shows that as more resources are devoted to programme administration, the unemployment reducing effect of training becomes stronger for the low-skilled. ${ }^{20}$

Moreover, the effect of policy continuity is significant for both population groups and has a negative effect as well, implying that a disruption of policy continuity is associated with an increase on the unemployment rate. The variable timing, which measures whether policies are implemented in a countercyclical or procyclical manner, matters too, but only through its interaction with ALMP spending (which is significantly positive for the unemployment rate of both population groups). It suggests that when policies are implemented in a countercyclical manner $($ timing $=1)$, the unemployment reducing effect of ALMPs is lower. ${ }^{21}$ This implies that policies that are implemented procyclically have a stronger unemployment reducing effect during booms but also a stronger unemployment enhancing effect during crises. This confirms the argument in favour of policy continuity, i.e. to invest in ALMPs not only during booms when resources are available but also during crises when the unemployed need that support the most. This argument is also confirmed by the cycle-timing interaction. It shows that when policies are implemented countercyclically, the elasticity of the unemployment rate to the cycle is lower.

Interestingly, the size of the coefficients arising from policy and implementation variables increases when interactions are included. ${ }^{22}$ This demonstrates that a correct implementation of policies enhances their unemployment reducing effect. These effects can be attributed to the benefits of individualized service delivery in the case of more generous job search conditions (Gaure et al. 2012; Kluve 2010), while continuity in implementation can generate mutual trust between labour market actors and employment service agencies.

Other control variables also show significant effects. As explained above in more detail, these variables have been included in the analysis to control for differences in the structure of the national labour markets (which may affect the speed of adjustment to 
shocks) and institutional arrangements (that can affect wage bargaining and macroeconomic performance) across countries, and avoid misspecifications in the model due to omitted variable bias. Their coefficients will not be analysed as they are not the central focus of this paper ${ }^{23}$ and their individual effects are (at least partly) already taken up by the other explanatory variables.

\subsubsection{Effects on the employment rate}

By and large, these findings show the mirror image of the unemployment rate's results. The different types of ALMPs (including training) have a positive effect on the employment rate of the overall and low-skilled populations. In line with previous results, ALMPs seem to be more effective in boosting the employment rate of the low skilled.

Likewise, the impact of implementation variables shows the mirror image of unemployment rate estimations; yet, in this case, the allocation of resources to programme administration has a positive and significant effect on the employment rate of both population groups (albeit only at the $10 \%$ level for the overall group). In addition, the interaction term between training and the allocation of resources to programme administration is significant and positively correlated, illustrating that as more resources are allocated towards PES and administration, the favourable effect of training on the overall and low-skilled employment rates becomes stronger.

Moreover, the effect of policy continuity is positive and significant for both groups, suggesting that ALMP spending stability has a boosting effect on both populations' employment rates. In addition, whether policies are implemented in a countercyclical or procyclical manner also influences the magnitude of the effect of ALMP spending on the employment rate of both population groups (i.e. this interaction term has a negative significant effect). This implies that when policies are implemented in a countercyclical manner (timing $=1$ ), the employment enhancing effect of policies is lower. This effect is, however, not confirmed by the cycle-timing interaction, which in the case of the employment rate is not significant for either population group.

\subsubsection{Effects on the labour force participation rate (LFPR)}

ALMPs have also significant effects on the LFPR of the overall and low-skilled populations. However, in this case, effects are not systematically positive or significant, particularly for the overall group. Combined to the effects on the unemployment and employment rates, these estimates allow us to assess whether positive effects result from workers transiting from unemployment to employment, or if in addition, policies are capable of reintegrating people back into the labour market. While training is positively and significantly correlated with the LFPR of the overall population, start-up incentives and employment incentives are positively and significantly correlated with the LFPR of the low skilled. Finally, the policy cluster is significant for both population groups, but while it appears to boost participation of the low skilled, it seems to be detrimental for the participation of the overall group. Looking at the full labour market picture, we can conclude that the beneficial effects of ALMPs on the employment rate result from both unemployed individuals finding jobs and inactive ones coming back to the labour market. The only exceptions are start-up incentives and the policy cluster, which seem to be fulfilling their activation role only among the low skilled, while for the overall population, they are mostly helping the unemployed move into employment. 
Implementation variables also play a key role in this case, particularly for the low skilled. An increased allocation of resources to programme administration has a positive and significant effect on the LFPR of the low skilled, both directly and through an interaction with training. ${ }^{24}$ Meanwhile, policy continuity has a positive and significant effect on both LFPR, in line with the employment rate findings. Similarly, the variable timing is significant for both population groups, but for the low-skilled only indirectly through its interaction with the overall expenditure in ALMPs. This negative effect is also in line with the low-skilled employment rate's findings, and its interpretation is the same as in the case of the employment and unemployment rates.

\subsection{IV effects relative to alternative models}

While I use the IV estimation as the preferred specification, I also estimate additional models as explained in the empirical strategy section in order to compare results, establish a benchmark and assess the extent of the reverse causality problem. Results of the IV estimation presented in Table 1 (and discussed above) broadly confirm the findings of other specifications.

Relative to OLS models estimated with fixed-effects and FGLS models fitted for panel data, the effects of ALMPs on labour market variables appear generally more effective in IV models, which account for the endogeneity of policy and implementation variables, with the exception of the unemployment rates, where OLS and FGLS coefficients are generally higher. Furthermore, while the effects of the PES allocation on labour market variables are higher across IV specifications, the opposite is true for the timing of policies. Overall, these findings are consistent with findings by Card (2001) that found that IV estimates are typically larger than OLS estimates.

\section{Interpretation of results and policy implications}

To provide an interpretation of the magnitude of the effects discussed above, I use the coefficients for the policy cluster and start-up incentives, which are particularly important for the low skilled, as basis for some calculations. According to the results, investing an additional US $\$ 1,000[\mathrm{PPP}]$ per unemployed in the policy cluster would reduce the overall unemployment rate by 1.6 percentage points and the low-skilled unemployment rate by around 2.2 percentage points. In terms of employment, raising expenditure on the policy cluster by US $\$ 1,000[\mathrm{PPP}]$ per unemployed would boost the overall employment rate by around two percentage points and the employment rate of the low skilled by 5.7 percentage points. Increased spending in these policies would also be associated with an improvement in the LFPR of the low skilled by 3.2 percentage points. As such, these policies appear to be more effective in improving labour market outcomes of the low skilled, which intuitively seems correct because they are targeted towards this more disadvantaged group. Moreover, this is in line with theoretical expectations since higher-skilled individuals are likely better equipped to find jobs by themselves and so policies targeted to them could appear less effective due a potential deadweight loss. The effect of start-up incentives is also nonnegligible. An increase by US $\$ 1,000$ [PPP] per unemployed in expenditure allocated to start-up incentives would be accompanied by around a 2.8 and 5.1 percentage point decrease in the unemployment rates of the overall and low-skilled populations, respectively, and larger increases in the employment rate of the overall and low-skilled populations, by 
around 3.2 and 9.2 percentage points, respectively. This is in line with micro-econometric evaluations of start-up incentives, which find that effects are larger for lower-educated individuals (Rodriguez-Planas 2010). In Germany, for example, authors detect a large increase in the long-term employment probability of low-educated individuals of around 24 percentage points (Caliendo and Künn 2011). However, as discussed below, for these macro effects to translate into higher levels of employment, countries would need to ensure spending in these programmes is commensurate with their unemployment levels.

As shown above, implementation has also significant effects, although economically small. For example, an increase by one percentage point in the allocation of resources to programme administration would be associated with a decrease of 0.1 percentage points in the overall unemployment rate, and an increase by around 0.1 and 0.2 percentage points in the low-skilled employment rate and LFPR, respectively. Furthermore, effects are systematically larger for the low-skilled.

Naturally, coefficients mean different things for countries depending on not only their level of unemployment but also their level of expenditure in each of the policies. For example, based on the above results, a country with a $10 \%$ unemployment rate (such as France or the United States in 2010) would need to spend around US\$5,600 (PPP) in training measures for every fewer unemployed (i.e. cost of reducing 1 for every 10 unemployed in a country with an unemployment rate of 10\%). Following the same logic, this same country would need to spend around US\$6,200 (PPP) in the policy cluster and US\$3,600 (PPP) in start-up incentives for every fewer unemployed. According to this, start-up incentives would be more effective in reducing unemployment than both the policy cluster and training. This finding is in line with results from microeconometric analyses showing that start-up incentives are associated with a double dividend' if subsidized firms create more jobs in the future (Caliendo and Künn 2014).

Unfortunately, countries usually spend less than the efficient levels of spending per unemployed individual. This is particularly the case with start-up incentives, in part because it is commonly believed that these policies benefit more the higher skilled who also need less government assistance. France, for example, would need to raise its expenditure per unemployed individual-relative to its 2010 expenditure-by over 65 and $640 \%$, respectively, in training and start-up incentives if the country is to attain the necessary levels for these policies to be the most effective. The story is different, however, for a country with a $20 \%$ unemployment rate such as Spain in 2010. In this country, the necessary expenditure in training to reduce by one the number of unemployed would be over US\$11,200 (PPP). In this case, start-up incentives would again offer a 'bigger bang for the buck' (around US\$7,300 [PPP] for one fewer unemployed). Yet, to attain this level of expenditure, Spain would need to increase by 1,850\% its 2010 spending in start-up incentives per unemployed individual, which seems unlikely.

As an exercise to understand the implication of these numbers from the country perspective, one could compare the efficient levels of spending in ALMPs presented above with costs for alternative options governments have for supporting unemployed individuals. ${ }^{25}$ On the one hand, with an annual median labour cost per employee in France in 2010 at around US\$38,500 (PPP), the necessary spending for the costliest ALMP (training at US\$5,600 [PPP] per unemployed) discussed above would seem both economically and socially more efficient than having the government employ these people directly. This is true even in a country like Spain, where an ALMP spending of around 
US $\$ 11,200$ (PPP) in training is still below the annual median labour cost per employee, which in 2010 was at around US\$33,400 (PPP). On the other hand, keeping unemployed individuals attached to the benefit system has also costs for the government and for society as a whole. Particularly for France, in 2010, the cost for society ${ }^{26}$ of having one unemployed under the out-of-work maintenance and support income was around US\$12,800 (PPP) per participant. In addition, the government spent over US $\$ 7,300$ (PPP) per participant in 2010 in income support measures, principally for the unemployed that had exhausted their entitlement to unemployment benefits. ${ }^{27}$ Importantly, the longer individuals are unemployed, the less likely it is for them to find jobs without assistance. As such, ALMPs will be nevertheless needed at some point or another to facilitate the return to work of these long-term unemployed individuals.

\section{Sensitivity analysis}

A number of robustness checks have been carried out to evaluate the sensitivity of the parameters discussed. First, the use of different samples (i.e. overall and low-skilled populations) in each labour market equation can be considered a first sensitivity test, as results are consistent between the two population groups analysed and mostly differ in terms of size of the coefficients. Second, the robustness of results was checked by excluding key countries (in terms of the relative size of their ALMP expenditure), namely Denmark, the Netherlands, Sweden, and Japan, ${ }^{28}$ and by running the regressions on EU countries only. Changing the sample does not seem to alter the big lines of the estimation results systematically for any group of countries. Some changes occur, however, such as (i) employment incentives are no longer significant for the unemployment rates of both groups when northern countries are excluded; (ii) training becomes favourable for the low skilled when Japan and northern countries are excluded; and (iii) some implementation effects gain significance when EU countries are analysed. Third, the window of time was also modified to assess whether results remained consistent when studying only the last decade. ${ }^{29} \mathrm{Re}-$ sults seem to hold, with the exception of the implementation variables timing and the interactions of the allocation of resources to programme administration with the policy variables that become highly significant for the unemployment rate.

Fourth, reduced estimations were also carried out, ${ }^{30}$ showing also coherent results. In particular, I estimated three reduced models for each dependent variable: the first model including only the four policy variables, the second model testing only implementation variables, and the third model with all policy and implementation variables. The findings presented throughout the paper are the result of this full model.

Fifth, alternative specifications as well as tests and post-estimation techniques were carried out as well. The overall coherence of the results across the different specifications used (i.e. OLS, FGLS with AR1 correction and IV models), illustrates the robustness of the empirical approach. Moreover, particular concerns affecting cross-country and time series models, such as the presence of heteroskedasticity, unit-roots ${ }^{31}$ and serial correlation, have been taken especially seriously and have been tested and tackled in various forms as described in the empirical strategy section. Importantly, all models were estimated with controls for (i) country-specific effects to account for unobservable cross-country differences and avoid biases that can occur when these differences are correlated with the other covariates ${ }^{32}$ and (ii) unobservable time-specific effects in 
order to account for labour market shifts that are common to all countries as a result of macroeconomic factors.

Finally, in an effort to assess the extent of the reverse causality problem that is commonly referred to in the labour market policy literature, the different models were estimated through an IV approach, using the lagged values of the endogenous variables as instruments in the models. Results, which are carried out through a 2SLS, are broadly confirmed by the other estimation techniques, giving confidence to the empirical results.

\section{Conclusions}

Since the 1990s, there has been increased recognition of the need for ALMPs, and today, these policies are widely regarded as an important tool in fighting unemployment. As a result, advanced countries devote significant public resources to ALMP spending. Yet, their success at the aggregate level remains contentious and incomplete. This is particularly true with regard to the specific impact by type of ALMP and the role of ALMPs' implementation characteristics in shaping their overall effects.

This paper contributes to this debate through an extended pooled cross-country and time series database for 31 advanced countries during the period 1985-2010. The contribution of this paper is threefold: first, it includes aspects of the delivery system in the analysis to shed light on the role of implementation characteristics in explaining differences in the performance of ALMPs; second, the analysis is disaggregated by type of ALMP to capture their differential effects; and third, it is focused on the labour market outcomes of the low skilled, who are among the least researched marginalized groups.

To capture the overall effects of ALMPs, I estimate six different models: three to measure the effects of ALMPs on labour market outcomes of the overall population (i.e. unemployment, employment and participation rates) and the other three to assess the effects on low-skilled individuals (i.e. unemployment, employment and participation rates). The paper estimates the effects of (i) six different ALMPs classified in four groups, training, employment incentives, start-up incentives and a policy cluster comprising policies mainly targeted to the most vulnerable groups (i.e. job rotation and job sharing, supported employment and rehabilitation, and direct job creation policies), and (ii) three dimensions of implementation, namely, allocation of resources to public administration, continuity and timing in the implementation of programmes. Moreover, given that implementation variables are closely related to policy intervention ones, interaction terms are included in the models.

I find that ALMPs matter at the aggregate level but mostly through appropriate implementation aspects. Start-up incentives and the policy cluster show the most favourable results, both in terms of reducing unemployment and also in terms of increasing employment. Moreover, these policies are effective in raising participation, but only for the low skilled. Coefficients of start-up incentives are higher, which according to micro-econometric analyses could be explained by the 'double dividend' associated to these policies, when subsidized firms create additional jobs (Caliendo and Künn 2014), particularly for low-skilled individuals who face limited options in the labour market (Caliendo and Künn 2011). Spending in employment incentives is also effective across the board, with the exception of the 
effect on the participation of the overall group that is not statistically significant. In addition, ALMPs seem to be more effective in improving labour market outcomes of the low skilled, something that is noteworthy as we know little from the existing literature on the net effects on these policies on low-skilled individuals. Training, in contrast, seems to be effective mostly for the overall population; however, it has also positive effects for the low skilled through the interaction with implementation variables.

In terms of implementation, results show that the allocation of resources to programme administration has favourable effects on labour market variables either directly or through its interaction with training policies. The effects of these interactions illustrate that as more ALMP resources are devoted to programme administration, the favourable effects of ALMPs on labour market variables become stronger. In addition, a disruption of policy continuity is associated with negative effects for all labour market variables analysed. The contrary occurs with the variable timing (i.e. measuring whether policies are implemented in a countercyclical or procyclical manner), which is nonsignificant in most cases. Interestingly, the size of the coefficients arising from policy and implementation variables once interactions are included is noticeably higher, which demonstrates that a correct implementation of policies enhances their beneficial effect.

\section{Endnotes}

${ }^{1}$ Including, Australia, Austria, Belgium, Canada, Czech Republic, Denmark, Estonia, Finland, France, Germany, Greece, Hungary, Ireland, Israel, Italy, Japan, Korea, Luxembourg, Mexico, the Netherlands, New Zeeland, Norway, Poland, Portugal Slovak Republic, Slovenia, Spain, Sweden, Switzerland, the UK and the USA.

${ }^{2}$ From around 20 to 25 years and from around 20 to 31 advanced economies.

${ }^{3}$ The exception is Bassanini and Duval (2006), which unlike other studies of the time, includes a complementary analysis disaggregating the unemployment effects by type of ALMP for 21 OECD countries over the period 1982-2003. This paper uses, thus, the previous OECD categorization of ALMPs, in force until 2002 (Grubb and Puymoyen 2008).

${ }^{4}$ The last decade has also seen an important development of tools and methodologies to treat a wider range of empirical problems, making these methods more robust when assessing aggregate effects.

${ }^{5}$ See Calmfors (1994), Layard et al. (1991) and Pissarides (1990) for an extended discussion on the definition and theoretical effects of ALMPs.

${ }^{6} \mathrm{~A}$ classification of the detailed expected effects by type of ALMP is available in Additional file 1: Table S3.

${ }^{7}$ In the case of ALMP policy analysis, this reverse causality stems from the fact that although the scale of ALMP provisions is meant to affect the size of unemployment, unemployment could also drive spending on ALMPs (e.g. if governments base their expenditure decisions on the magnitude of the problem they wish to address).

${ }^{8} \mathrm{PES}$ and administration represented close to $30 \%$ of total expenditure in ALMPs in 2010. When this item is taken into account, training, for example, represents $26.5 \%$ of total expenditure in 2010. 
${ }^{9}$ The ratio of government expenditure in ALMPs to GDP has also been used as dependent variable (OECD 1993). This would imply that governments commit a given fraction of GDP to spending in ALMP over the medium term, which does not adjust with the unemployment rate. In this paper, this definition does not seem to represent the correct policy stance of governments since in our sample of countries, the ratio of ALMPs to GDP does not remain constant over time. It declines even when considering only periods of economic growth.

${ }^{10}$ From now on, 'allocation of resources to program administration' or 'PES allocation'.

${ }^{11}$ Which is defined by governments' expenditure in PES (Additional file 1: Table S1).

${ }^{12}$ Other interactions were tested through individual and joint tests for the nonsignificance of interactions terms but failed to pass the tests so were not included in the specifications.

${ }^{13}$ The cycle is measured by the GDP in real terms.

${ }^{14}$ Section 1 of the Additional file 1 provides a detailed explanation on the construction of the database. It also includes a discussion regarding data comparability, owing to the country-specific nature of the policy intervention variables and the change in the OECD classification system on policy interventions in 2002.

${ }^{15} \mathrm{~A}$ variety of econometric estimators, technical fixes and diagnostic tests exist today to treat the endogeneity issue, which have been successfully used in economic empirical analyses (Halla et al. 2016; Overesch and Rincke 2011), including those studying labour market policies and institutions (Holden and Sparrman 2017; Hijzen and Martin 2013).

${ }^{16}$ The model was also tested for heteroskedasticity using the robust option available. Robust results did not differ much from non-robust results.

${ }^{17}$ The variables employment incentives and start-up incentives were not included among the endogenous variables given tests' results. When the orthogonality conditions of the model were tested including these variables as exogenous, the $C$ test indicated robust results.

${ }^{18}$ See Holden and Sparrman (2017) for relevant recent literature using these tests.

${ }^{19}$ Caliendo and Künn (2011) find that although effects of the start-up incentive programme studied are also positive for individuals with high education/high qualification, effects are much larger for individuals with low education/low qualification. They detect that increase in the long-term employment probability of low-educated participants is 23.7 percentage points.

${ }^{20}$ The graphic interpretation of the different interaction effects is available upon request.

${ }^{21}$ Given the equation of the interaction effect: unr $=a+$ b1 almp + b2 (almp"timing) $+\mathrm{b} 3$ timing $+e$, the effect of the interaction term when timing $=1$ is given by unr $=(\mathrm{b} 1+\mathrm{b} 2)^{*}$ almp $+\mathrm{b} 3$ and the effect of the interaction term when timing $=0$ is given by unr $=$ b1*almp.

${ }^{22}$ Regression results adding one interaction at a time are available in Additional file 1: Table S5.

${ }^{23}$ Studies that focus on the macroeconomic effects of labour market institutions and reforms, of which ALMPs are one component, can shade light on the particular effects of these institutional variables (e.g. Murtin and de Serres 2014; Blanchard and Wolfers 2000; Scarpetta 1996). 
${ }^{24}$ It is important to note, that in the case of the LFPR of the overall population, individual and joint tests for the non-significance of interactions terms could not be rejected so all interactions were dropped from the equation.

${ }^{25}$ This exercise is not intended as a cost-benefit analysis, whose complexity would call for more detailed data and complex methods than those used.

${ }^{26}$ This mainly includes the cost of the unemployment insurance system, $50 \%$ of the special employment assistance program (AEPE) bared by the unemployment insurance system and $40 \%$ of the specific solidarity allowance and pension equivalent allowance financed by the solidarity contributions of state employees (author's calculations based on Eurostat 2013).

${ }^{27}$ This includes the cost of the partial unemployment scheme (transferred to enterprises), the temporary delay allowance (ATA), 50\% of the special employment assistance (AEPE) bared by the Central government, and $60 \%$ of specific solidarity and pension equivalent allowances financed by the state budget (Ibid).

${ }^{28}$ Japan's exclusion aims to ensure that the country's potential data limitations (Grubb and Puymoyen 2008) are not invalidating the findings of the paper. Please refer to Section 1 of the Additional file 1, for details on these potential data limitations.

${ }^{29}$ Results changing the sample of countries and the window of time are available in Additional file 1: Table S6.

${ }^{30}$ Results available upon request.

${ }^{31}$ To control for the non-stationarity of dependent variables, I used the augmented Dickey-Fuller test before running the estimations. In all cases, the tests rejected the null hypotheses of non-stationarity.

${ }^{32}$ Results with and without country-specific effects are available in Additional file 1: Table S6. An interesting difference between models estimated with and without country-specific fixed-effects is that the size of the start-up incentives' coefficients becomes smaller when country-specific fixed-effects are added to the estimations.

\section{Additional file}

Additional file 1: The Additional file provides further information on the construction of the database (section 1), the exact definitions of variables and their sources of information (Table S1), a summary of the first-stage regressions (Table S2), a classification of the detailed expected effects by type of ALMP (Table S3), descriptive statistics of the variables used in the analysis (Table S4), and robustness checks to evaluate the sensitivity of the parameters discussed (Table S5 and Table S6). (DOCX $171 \mathrm{~kb})$

\section{Acknowledgements}

I would like to thank Philippe Askenazy (ENS) for the precious and continuous guidance and support during the whole preparation of this paper, Miguel Ángel Malo (University of Salamanca) for the invaluable advice on several versions of the paper and David Margolis (PSE), Günther Schmid (Social Science Research Center - WZB and Free University Berlin), Michele Pellizzari (Université de Genève), Sangheon Lee (ILO), Steven Tobin (Labour Market Information Council), Thomas Breda (PSE), Thomas Piketty (PSE) and four referees for the excellent feedback and practical suggestions on earlier drafts. I would also like to thank Louise Nennen for the excellent research assistance as well as the anonymous referee and the editor of this journal for their valuable suggestions. The views expressed herein are those of the author and do not necessarily reflect the views of the International Labour Organization.

Responsible editor: Denis Fougère 
Availability of data and materials

The data and materials are available upon request.

\section{Competing interests}

The IZA Journal of Labor Policy is committed to the IZA Guiding Principles of Research Integrity. The author declares that she has observed these principles.

\section{Publisher's Note}

Springer Nature remains neutral with regard to jurisdictional claims in published maps and institutional affiliations.

Received: 22 October 2017 Accepted: 31 January 2018

Published online: 08 March 2018

\section{References}

Agnolucci P, Flachenecker F, Söderberg M (2017) The causal impact of economic growth on material use in Europe. J Environ Econ Policy 6:415-432. https://doi.org/10.1080/21606544.2017.1325780

Algan Y, Cahuc P, Zylberberg A (2002) Public employment and labour market performance. Econ Policy 17:7-66

Armingeon K (2007) Active labour market policy, international organizations and domestic politics. J European Public Policy 14:905-932. https://doi.org/10.1080/13501760701497923

Baker D, Glyn A, Howell DR, Schmitt J (2005) Labor market institutions and unemployment: a critical assessment of the cross-country evidence. In: Howell DR (ed) Fighting unemployment: the limits of free market orthodoxy. Oxford University Press, Oxford

Bassanini A, Duval R (2006) Employment patterns in OECD countries: reassessing the role of policies and institutions, OECD social, employment and migration working papers no. 35. OECD Publishing, Paris

Bassanini A, Duval R (2009) Unemployment, institutions, and reform complementarities: re-assessing the aggregate evidence for OECD countries. Oxf Rev Econ Policy 25:40-59. https://doi.org/10.1093/oxrep/grp004

Baum C, Shaffer M, Stillman S (2007) Enhanced routines for instrumental variables/generalized method of moments estimation and testing. Stata J 7:465-506

Bellmann L, Jackman R (1996a) Aggregate impact analysis. In: Schmid G, O'Reilly J, Schömann K (eds) International handbook of labour market policy and evaluation. Edward Elgar, Cheltenham, pp 143-162

Bellmann L, Jackman R (1996b) The impact of labour market policy on wages, employment and labour market mismatch. In: Schmid G, O'Reilly J, Schömann K (eds) International handbook of labour market policy and evaluation. Edward Elgar, Cheltenham, pp 725-746

Blanchard O, Wolfers J (2000) The role of shocks and institutions in the rise of European unemployment: the aggregate evidence. Econ J 110:1-33. https://doi.org/10.1111/1468-0297.00518

Büttner T, Prey H (1997) Does active labour market policy affect structural unemployment? An empirical investigation for west German regions, 1986 to 1993, CILE discussion paper no. 42. Universität von Konstanz, Konstanz

Caliendo M, Künn S (2011) Start-up subsidies for the unemployed: long-term evidence and effect heterogeneity. J Public Econ 95:311-331. https://doi.org/10.1016/j.jpubeco.2010.11.003

Caliendo M, Künn S (2014) Regional effect heterogeneity of start-up subsidies for the unemployed. Reg Stud 48:1108-1134. https://doi.org/10.1080/00343404.2013.851784

Calmfors L (1994) Active labour market policy and unemployment—a framework for the analysis of crucial design features, OECD economic studies, no. 22. OECD publishing, Paris

Calmfors L, Lang H (1995) Macroeconomic effects of active labour market programmes in a union wage-setting model. Econ J 105:601-619. https://doi.org/10.2307/2235020

Card D (2001) Estimating the return to schooling: progress on some persistent econometric problems. Econometrica 69:1127-1160. https://doi.org/10.1111/1468-0262.00237

Card D, Kluve J, Weber A (2010) Active labor market policy evaluations: a meta- analysis. Econ J 120:452-477. https:// doi.org/10.1111/j.1468-0297.2010.02387.x

Card D, Kluve J, Weber A (2017) What works? A meta analysis of recent active labor market program evaluations. J Eur Econ Assoc 0:1-38. https://doi.org/10.1093/jeea/jvx028

Clasen J, Clegg D (2006) Beyond activation: reforming European unemployment protection systems in post-industrial labour markets. Eur Soc 8:527-553. https://doi.org/10.1080/14616690601002582

Dahlberg M, Forslund A (2005) Direct displacement effects of labour market programmes. Scand J Econ 107:475-494. https://doi.org/10.1111/j.1467-9442.2005.00419.x

Dolado JJ, Garcia-Serrano C, Jimeno JF (2002) Drawing lessons from the boom of temporary jobs in Spain. Econ J 112: F270-F295

Drukker DM (2003) Testing for serial correlation in linear panel-data models. Stata J 3:168-177

Elmeskov J, Martin J, Scarpetta S (1998) Key lessons for labour market reforms: evidence from OECD countries' experiences. Swed Econ Policy Rev 5:205-258

Escudero V, López Mourelo E (2017) The employment effect of changes in the composition of fiscal consolidations. Int Rev. Appl Econ 31:45-68. https://doi.org/10.1080/02692171.2016.1221388

Estevão M (2003) Do active labor market policies increase employment, IMF working papers no. 03/234. International Monetary Fund, Washington DC

Eurostat (2013) Labour market policy statistics: France 2011. Qualitative report. European Commission, Brussels

Gaure S, Roed K, Westlie L (2012) Job search incentives and job match quality. Labour Econ 19:438-450. https://doi.org/ 10.1016/j.labeco.2012.04.001

Grubb D, Puymoyen A (2008) Long time series for public expenditure on labour market programmes, OECD social, employment and migration working papers no. 73. OECD Publishing, Paris 
Halla M, Lackner M, Scharler J (2016) Does the welfare state destroy the family? Evidence from OECD member countries. Scand J Econ 118:292-323. https:/doi.org/10.1111/sjoe.12144

Heylen F (1993) Labour market structures, labour market policy and wage formation in the OECD. Labour 7:25-51. https://doi.org/10.1111/j.1467-9914.1993.tb00195.x

Hijzen A, Martin S (2013) The role of short-time work schemes during the global financial crisis and early recovery: a cross-country analysis. IZA J Labor Policy 2:1-31. https://doi.org/10.1186/2193-9004-2-5

Holden S, Sparrman V (2017) Do government purchases affect unemployment? Scand J Econ 120:124-158. https://doi. org/10.1111/sjoe.12214

International Labour Organization (ILO) (2016) What works: active labour market policies in Latin America and the Caribbean. Studies on growth with equity. ILO, Geneva

Kahn L (2012) Labor market policy: a comparative view on the costs and benefits of labor market flexibility. J Policy Anal Manag 31:94-110. https://doi.org/10.1002/pam.20602

Kluve J (2010) The effectiveness of European active labor market programs. Labour Econ 17:904-918. https://doi.org/10. 1016/j.labeco.2010.02.004

de Koning J (1993) Measuring the placement effects of two wage-subsidy schemes for the long-term unemployed. Empir Econ 18:447-468. https://doi.org/10.1007/BF01176198

de Koning J (2001) Aggregate impact analysis of active labour market policy: a literature review. Int J Manpow 22:707-735. https://doi.org/10.1108/EUM0000000006507

de Koning J, van Nes PJ (1991) A quantitative approach to process evaluation: the case of the Vermeend-moor act. Gov Policy 9:111-118. https://doi.org/10.1068/c090111?id=c090111

Lalive R, van Ours JC, Zweimüller J (2005) The effect of benefit sanctions on the duration of unemployment. J Eur Econ Assoc 3:1386-1417

Larsen CA (2002) Policy paradigms and cross-national policy (mis)learning from the Danish employment miracle. J Eur Public Policy 9:715-735. https://doi.org/10.1080/13501760210162320

Layard R, Nickell S, Jackman R (1991) Unemployment: macroeconomic performance and the labour market. Oxford University Press, Oxford

Layard R, Nickell S, Jackman R (2009) Unemployment: macroeconomic performance and the labour market. Oxford University Press, Oxford

Lusinyan L, Bonato L (2007) Work absence in Europe, IMF staff paper, no.54. International Monetary Fund, Washington DC

Martin JP (2015) Activation and active labour market policies in OECD countries: stylized facts and evidence on their effectiveness. IZA J Labor Policy 4:1-29. https://doi.org/10.1186/s40173-015-0032-y

Martin JP, Grubb D (2001) What works and for whom: a review of OECD countries' experience with active labour market policies. Swed Econ Policy Rev 8:9-56

Murtin F, de Serres A (2014) How do policies affect the exit rate out of unemployment? Disentangling job creation from labour market frictions. Labour 28:190-208. https://doi.org/10.1111/labr.12029

Organisation for Economic Co-operation and Development (OECD) (1993) Active labour market policies: assessing macroeconomic and microeconomic effects. OECD Employment Outlook, Paris

Overesch M, Rincke J (2011) What drives corporate tax rates down? A reassessment of globalization, tax competition, and dynamic adjustment to shocks. Scand J Econ 113:579-602. https://doi.org/10.1111/j.1467-9442.2011.01650.x

Pissarides C (1990) Equilibrium unemployment theory. MIT Press, Cambridge

Rodriguez-Planas N (2010) Channels through which public employment services and small business assistance programmes work. Oxf Bull Econ Stat 72:458-485. https://doi.org/10.1111/j.1468-0084.2010.00593.x

Roodman D (2006) How to do xtabond2: an introduction to difference and system GMM in Stata, working paper no. 103. Center for Global Development, Washington DC

Scarpetta S (1996) Assessing the role of labour market policies and institutional settings on unemployment: a cross-country study. OECD Econ Stud 26:43-98

Schmid G (1996) New public management of further training. In: Schmid G, O'Reilly J, Schömann K (eds) International handbook of labour market policy and evaluation. Edward Elgar, Cheltenham, pp 725-746

Schmid G, Speckesser S, Hilbert C (2001) Does active labour market policy matter? An aggregate impact analysis for Germany. In: de Koning J, Mosley H (eds) Labour market policy and unemployment: impact and process evaluations in selected European countries. Edward Elgar, Cheltenham, pp 78-114

Wooldridge JM (2010) Econometric analysis of cross section and panel data, 2nd edn. MIT Press, Cambridge 